\title{
Enhancing the Removal of Phenolic Compounds from Palm Oil Mill Effluent by Enzymatic Pre-treatment and Microwave-Assisted Extraction
}

\author{
N. SAIFUDDIN ${ }^{1}$, A. SALTANAT ${ }^{2}$ and H. REFAL ${ }^{1}$ \\ ${ }^{1}$ Centre of Renewable Energy, UniversitiTenagaNasional, Jalan IKRAM-UNITEN, \\ 43000 Kajang, Selangor, Malaysia \\ ${ }^{2}$ Kazakh National Technical University (Named after K. Satpaev) Almaty, Kazakhatan \\ saifuddin@uniten.edu.my
}

Received 13 December 2013 / Accepted 2 January 2014

\begin{abstract}
Palm oil mill effluent (POME), generated by the oil extraction industry, represents a severe environmental problem due to its highly polluting organic load arising from polyphenol content with low biodegradability. However, with its more than dozens of phenolic compounds, POME is also regarded as a potent source of natural antioxidants. This study describes the improvement in the extraction efficiency of phenolic compounds after pre-treatment with hydrolytic enzymes and microwave irradiated extraction. Enzymatic hydrolysis of POME by various amylolytic enzymes was investigated to reveal the potential coupling mechanism of microwave irradiation-enzyme coupling catalysis (MIECC). It was shown that a 5-6 min extraction time was enough for complete leaching of the phenolic compounds using microwave irradiation. The microwave irradiation extraction (MIE) aided with ragi tapai hydrolysis had $16.3 \%$ higher yield of phenolic compounds as compared to microwave irradiation without enzymatic hydrolysis and increase by $34.7 \%$ when compared with maceration method.
\end{abstract}

Keywords: Palm oil mill effluent, Enzymatic hydrolysis, Microwave irradiated extraction, Nonthermal effects, Ragi tapai

\section{Introduction}

Oil palm production is a major agricultural industry in Malaysia which has become the most important agriculture-based industry in this country. Malaysia the biggest palm oil producer worldwide $^{1}$ and the number of palm oil mills in Malaysia has increased tremendously, from about 10 mills in $1960^{2}$ to 410 operated mills in $2008^{3}$. However, the rapid development of the industry has had serious consequences on the natural environment, which mainly related to water pollution due to a large discharge of untreated or partially treated palm oil mill effluent (POME) into watercourses.

The oil palm fruits grow in bunches (called as Fresh Fruit Bunches (FFB)) and can weigh about 45-75 kg when fully ripe. The FFB are harvested and sent to the palm oil mills 
for processing. At the palm oil mill, the FFB first undergo sterilization to halt the enzymatic lipolysis which otherwise, will cause rises in the free fatty acids content. The fruit nuts are separated from the sterilized FFB by a threshing process. The fruit nuts were then pressed for its oil while the empty fruit branches (EFB), which consists of about $20-25 \%$ stalk and $75-80 \%$ spikelets is discarded or used as biomass ${ }^{4}$. The palm oil extracted contains mainly triglycerides and variety of phytonutrients, i.e., carotenes, tocopherols, tocotrienols, squalene, sterols and coenzyme $Q^{5-10}$ reported the presence of the phenolics in the oil palm fruits in FFB. The sterilization process in the oil palm mill which uses steam has possibly caused the phenolics in FFB to be washed away with water and ended up in the palm oil mill effluent and a method was developed to extract the phenolic from POME ${ }^{11}$. Palm oil mill effluent is a liquid by-product derived mainly from the sterilizer condensate and the centrifugal desludging of raw palm oil fruits from the screw press. It is regarded as industrial waste and requires extensive treatment before discharge. POME is an acidic brownish colloidal suspension characterized by high contents of organics and solids and is discharged at a temperature of $80-90{ }^{\circ} \mathrm{C}$. It has been estimated that POME contributes to about $30 \%$ of the total biochemical oxygen demand (BOD) load exerted on the Malaysian aquatic environment. Specifically, the amount of POME generated is approximately $3.8 \mathrm{~m}^{3}$ for each ton of CPO produced ${ }^{12}$. Table 1 shows the typical characteristic of POME. POME is a non-toxic waste, as no chemical is added during the oil extraction process, but will pose environmental issues due to large oxygen depleting capability in aquatic system due to organic and nutrient contents. The high organic matter is due to the presence of different sugars such as arabinose, xylose, glucose, galactose and manose. The suspended solids in the POME are mainly oil-bearing cellulosic materials from the fruits. The challenge of converting such agricultural waste into high value products is currently being explored actively.

Table 1. Characteristics of raw POMEand the regulatory discharge limits

\begin{tabular}{lcc}
\hline Parameter & Value $^{*}$ & Regulatory discharge limit \\
\hline Temperature, ${ }^{\circ} \mathrm{C}$ & $80-90$ & 45 \\
$\mathrm{pH}$ & 4.7 & $5.0-9.0$ \\
BOD, 3 days at $30{ }^{\circ} \mathrm{C}$ & 25,000 & $100(50)$ \\
Chemical oxygen demand (COD) & 50,000 & - \\
Total solids (TS) & 40,000 & - \\
Total suspended solids (TSS) & 18,000 & 400 \\
Total volatile solids (TVS) & 34,000 & - \\
Oil and grease (O\&G) & 4,000 & 50 \\
Ammonia-nitrogen (NH $\left.{ }_{3}-\mathrm{N}\right)$ & 35 & 150 \\
Total Kjeldahl Nitrogen (TKN) & 750 & 200 \\
\hline
\end{tabular}

*All values, except $p H$ and temperature, are expressed in $m g L^{-1} ; P O M E=$ Palm oil mill effluent Sources: ${ }^{13 ;} 14$

Currently, recovery of renewable organic-based product is a new approach in managing POME, whereby the extraction of by-products such as volatile fatty acid, biogas and polyhydroxy alkanoates can help to promote sustainability of the palm oil industry. Recently, natural antioxidants have become very popular for medical and food applications and are preferred by consumers than synthesized antioxidants. For instance, the use of agricultural wastes as alternative low-cost sources of phenolic compounds has been on the increase. Extraction is the first step in the commercial isolation of these antioxidant compounds. 
This study reports the extraction and analyses of various types of phenolic compounds in POME. These phenolic compounds in POME are water soluble and have powerful antioxidant properties. Phenolic compounds the most widely occurring groups of phytochemicals in the plants and are a major source of natural antioxidants in human diet. Lignans and total phenolic compounds are commonly extracted by using mixed solvents, such as dioxane/ethanol, water/acetone, water/methanol and water/ethanol, followed by an ultrafiltration step for their recovery. Additionally, they can be extracted with the aid of alkaline or acid (e.g., hydrochloric acid) hydrolysis, but this method could be destructive for the target compounds whether too long heating periods or too high concentrations are used. Alternatively, to improve plant polyphenol extraction efficiency, the use of carbohydratehydrolyzing enzymes, such as pectinase, cellulase, hemicellulase and glucanase has been recently introduced to release phenolic compounds that are trapped in cell walls matrix and other solids found in the wastewater ${ }^{15,16}$. These enzymes might play a role in disintegrating the plant cell wall matrix and facilitating the polyphenol extraction ${ }^{17-20}$. In order to seek more environmentally friendly methods, decrease the solvent consumption, shorten the extraction time, increase the extraction yield and enhance the quality of extracts, various novel extraction techniques have been developed for the extraction of nutraceuticals from plants, including ultrasound-assisted extraction, supercritical fluid extraction, microwaveassisted extraction and accelerated solvent extraction ${ }^{21}$. Microwave extraction of phenolic compounds from Rosmarinus officinalis, Origanum dictamnum and Vitexagnus (cactus) has been studied ${ }^{22}$. Microwaves affect the polar molecules in the extraction media and this has an effect on enhancing the extraction efficiency of the microwave-assisted extraction ${ }^{23}$. It was found that microwave extraction increased extraction yield and decreased solvent amount. Phenolic compounds and antioxidants were obtained from buckwheat by microwave using different solvents, such as water, ethanol, and a water-ethanol mixture; the water-ethanol mixture was found to give the best results ${ }^{24}$.

Microwave-assisted processes are among several dominant trends of the 'green chemistry', applying the accelerated microwave irradiation as an alternative reaction condition in chemical processes. Microwave irradiation is the electromagnetic irradiation with frequency range of $0.3-300 \mathrm{GHz}$. Most of the reported microwave chemistry experiments are conducted at $2450 \mathrm{MHz}$ (the corresponding wavelength is $12.24 \mathrm{~cm}$ ) since this frequency is approved worldwide and used in commercial microwave equipment available currently. One reason is that near to this frequency, the microwave energy absorption by liquid water is maximal. The influence of microwave energy on chemical or biochemical reactions is both thermal and non-thermal. The principle of microwave energy is based on its direct impact on polar solvents and is governed by two mechanisms: ionic conduction (occurs in a solution containing ions when electromagnetic field is applied) and dipole rotation (realignment of the dipoles with the applied field) ${ }^{25}$. For microwave assisted reactions, the solvent must have high both dielectric constant and dissipation factor, i.e., the ability to absorb microwave energy and pass it on asheat to the surrounding molecules ${ }^{25,26}$. Consequently, polar solvents and ionic solutions (acids) will strongly absorb microwave energy because of their permanent dipole moment, while non-polar solvents will not heat up when exposed to microwaves. The efficiency of the MAE depends on the used solvent, duration of the process, applied temperature and microwave power.

Therefore, the objective of this study is to determine the best extraction conditions to obtain the phenolic compounds from POME using microwaveirradiation aided with enzymatic treatment. Enzymatic coupled with microwave extraction is expected to have 
impressive effects with characteristics of high catalytic efficiency, high specificity, mild reactive conditions and preserving the original efficacy of active compounds to the maximum. However, the application of the combination of these two methods specifically on POME has not been reported, while reports on other plant materials are also limited.

\section{Experimental}

POME samples were derived from the final pond of West Palm Oil Mill, Sime Darby Plantation Sdn. Bhd. Carey Island, Klang, Malaysia. The POME, in liquid form was allowed to cool to $45-50{ }^{\circ} \mathrm{C}$ before being poured into plastic containers $(10 \mathrm{~L})$. The containers were sealed tight and labelled before being transported to the UNITEN laboratory. In the lab, the POME was filtered through $5 \mathrm{~mm}$ sieve to remove heavy suspended solids. The samples were then stored multiple tightly capped plastic containers (2 L each) at $4{ }^{\circ} \mathrm{C}$ until further used in order to prevent the wastewater from undergoing biodegradation due to microbial action.

The commercial ragi tapai (which contains the hydrolytic enzymes) was obtained from the local market in Kajang Selangor. The ragi tapai is cheaply available in local market. Tapai is a traditional fermented food popular in Malaysia and Indonesia. Microorganisms found in the traditional ragi tapai are moulds (Rhizopus oryzae, Amylomyces rouxii, Mucor $s p$. and Candida utilis) and yeasts. The moulds are strong amylolytic ${ }^{27}$. Trifluoroacetic acids (TFA), Follin-Ciocalteu phenol reagent (2,4,6-tripridyl-s-triazine), gallic acid and sodium carbonate were obtained from Sigma (St. Louis, USA). Ultrapure deionized water was obtained using the ELGA Lab Water (UK) water purification system in our laboratory and was used to prepare all the solutions.

\section{Methodology}

\section{Determination of Characteristics of POME}

Sufficient quantities of POME were withdrawn from the cold storage and allowed to reach to room temperature $\left(25 \pm 3{ }^{\circ} \mathrm{C}\right)$ before use. Determination of $\mathrm{TS}, \mathrm{SS}, \mathrm{O} \& \mathrm{G}$ and $\mathrm{pH}$ were carried out in accordance with the standard method for the examination of water and wastewater $^{28}$. Three replicates were analysed for each sample.

\section{Sample preparation}

Sedimentation is a common physical separation technique that is practiced prior to further treatment of POME to reduce suspended solid (SS) concentration. Cold ( $\left.4{ }^{\circ} \mathrm{C}\right)$ POME sample were taken out and brought to room temperature $\left(25 \pm 3{ }^{\circ} \mathrm{C}\right)$. In this study separation was carried out using short exposure (100s) of microwave irradiation at a power of $300 \mathrm{~W}$. Microwave treatments were carried out using a domestic microwave oven (Samsung, CE2877N, Korea) with an operating frequency of $2450 \mathrm{MHz}$. The microwave oven provided microwave radiation at variable power levels of $100 \mathrm{~W}, 180 \mathrm{~W}$, $300 \mathrm{~W}, 450 \mathrm{~W}, 600 \mathrm{~W}$ and $850 \mathrm{~W}$.

After microwave irradiation, the bottom layer which was a result of dense coagulation of suspended solid was collected. The top layer (supernatant) from the microwave irradiation sedimentation was centrifuged at $3000 \mathrm{x}$ g for $30 \mathrm{~min}$ at room temperature. The bottom layer obtained after centrifugation was collected and pooled together with the bottom layer obtained from the earlier microwave irradiation step. The pooled sedimentation was then freeze dried (lyophilized). The powder was transferred into a vial and kept at $-20{ }^{\circ} \mathrm{C}$, until further use. 


\section{Extraction of phenolic compounds}

\section{Maceration extraction}

Maceration was done at $40 \pm 1{ }^{\circ} \mathrm{C}$ for comparison with the microwave assisted extraction. The lyophilized POME sample (10 g each) was transferred to four different $250 \mathrm{~mL}$ capped bottles and dissolved with $150 \mathrm{~mL}$ of different solvents (50\% ethanol, 80\% methanol, acetone, water). The extraction was carried out in a shaking water bath (Protech, Malaysia) at $40{ }^{\circ} \mathrm{C}$, at $150 \mathrm{rpm}$ for different period (2, 4, 6, 8, 10 and $\left.12 \mathrm{~h}\right)$. The extracts obtained were filtered over a Whatman No. 1 paper. Methanol, ethanol and acetone filtrates were concentrated under vacuum but the water extract was freeze-dried. Extracts to be analyzed were kept in $20 \mathrm{~mL}$ dark-colored bottles in a refrigerator before the analysis.

\section{Enzymatic hydrolysis and microwave irradiation extraction}

A domestic microwave oven (Samsung CF3110N-5, Korea) was modifiedwith addition of a magnetic stirrer, water condenser, and temperature probe as shown in Figure $1^{29}$. The lyophilized POME sample (10 g each) was transferred to four different $250 \mathrm{~mL}$ capped bottles and dissolved with $200 \mathrm{~mL}$ of different solvents (50\% ethanol, $80 \%$ methanol, acetone, water) and were irradiated under microwave at $180 \mathrm{~W}$ power in the following cyclic manner: irradiation for $20 \mathrm{~s}$ followed by $15 \mathrm{~s}$ power off. This irradiation pattern was repeated to give final number of cycles as 3, 6, 9, 12 and 15.

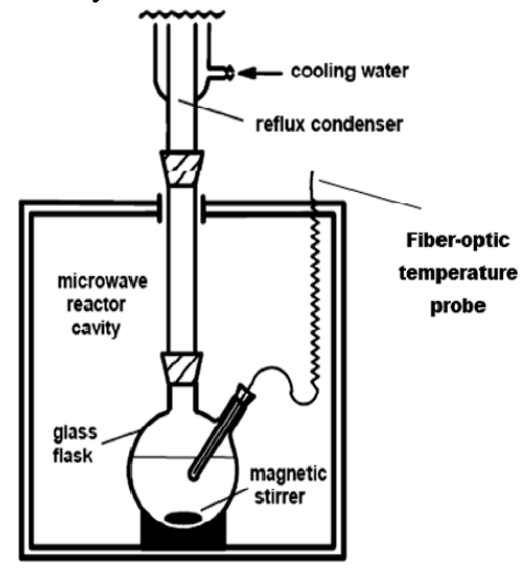

Figure 1. Microwave irradiation extraction using a modified domestic microwave oven

For the enzymatic hydrolysis couple with microwave irradiated extraction, the similar process was followed but the samples (lyophilized POME; $10 \mathrm{~g}$ ) were first mixed with $10 \mathrm{~g}$ of ragi tapai and then dissolved in $200 \mathrm{~mL}$ of different solvents as stated above. All other conditions were kept the same as the non-enzymatic microwave irradiated extraction method.

\section{Estimation of total phenolics}

The extracts obtained from both methods were filtered over a Whatman No. 1 paper. Methanol, ethanol and acetone filtrates were concentrated under vacuum below $45^{\circ} \mathrm{C}$ in a rotary evaporator until about $5 \mathrm{~mL}$ of the filtrate remained. For the waterextract the filtrate was freeze-dried. The extracts were re-dissolved in ultrapure water to final volume of $10 \mathrm{~mL}$. The Folin-Ciocalteu method ${ }^{30}$ was used for the determination of total phenolic content (TPC). Gallic acid was used as a standard. An aliquot, $0.5 \mathrm{~mL}$ of extract was added to $0.5 \mathrm{~mL}$ of FolinCiocalteu's phenol reagent and vortex for $10 \mathrm{~s}$. After standing for $2 \mathrm{~min}$ at room temperature, 
$10 \mathrm{~mL}$ of $7 \%$ sodium carbonate $\left(\mathrm{Na}_{2} \mathrm{CO}_{3}\right)$ was added to the mixture. The mixture was then allowed to react at room temperature $\left(28 \pm 2{ }^{\circ} \mathrm{C}\right)$ for $60 \mathrm{~min}$. The absorbance was then measured at $715 \mathrm{~nm}$ using UV-Vis spectrophotometer (Shimadzu, Kyoto, Japan) and converted into total phenolic content using gallic acid standard curve. Standards of difference concentration (from 0 to $1 \mathrm{mg} / \mathrm{mL}$ of gallic acid) were prepared to make the standard curve. Dilutions were made so as to obtain the absorbance reading within the limits of the calibration curve. The amount of total phenolics was expressed as milligrams of gallic acid equivalents (GAE) in $10 \mathrm{~g}$ of lyophilized POME. Distilled water was used as a blank for the background subtraction. All measurements were done in triplicates.

\section{Results and Discussion}

\section{Characteristics of palm oil mill effluent (POME)}

The samples of POME were analyzed for oil and grease (O\&G) and totalsolid (TS) content using the standard methods. The characteristic of POME used in this experiment showed an average content of O\&G and TS as $4.4 \mathrm{~g} / \mathrm{L}$ and $42.3 \mathrm{~g} / \mathrm{L}$ respectively, which were comparable to the values from previous studies ${ }^{13}$.

It has been reported that at temperature of $55^{\circ} \mathrm{C}$, the POME will settled into two layers after sitting for 3-4 h. The percentage of top layer will increase if the settling is continued for longer time (20-24 h) ${ }^{31}$. Using microwave irradiation at $300 \mathrm{~W}$ of power and duration of 100 s, the POME was separated into two layers. The volume percentage of the top layer (liquid supernatant) was about $58 \%$ and the bottom layer, which was semi-solid, was about $42 \%$. The bottom layer appears to be a result of dense coagulation of suspended solids. The bottom layer was re-suspended in distilled water in a ratio of 2: $1(\mathrm{v} / \mathrm{v})$ (bottom layer: water). The suspension was mix thoroughly using a magnetic stirrer at medium speed for $5 \mathrm{~min}$. The top layer supernatant was centrifuged (3000 $\mathrm{xg}$ ) for $20 \mathrm{~min}$, to extract any soluble matter still trapped in the top layer which was not extracted in the initial separation. The sediments from both the extraction was pooled and then lyophilized. The analysis of the top layer showed that microwave aided settling of the POME provided almost 95\% of SS removal when compared to the original POME. It was noticed that no oil layer was observed during settling. Short duration (100 s) of microwave irradiation at low power (300 W) appears to be an efficient method of sedimentation, with high percentage of SS removal (95\%). This result shows microwave irradiation provides a very rapid sedimentation process which otherwise would take $20-24 \mathrm{~h}$ at $55^{\circ} \mathrm{C}$ for similar result ${ }^{31}$.

\section{Extraction of total phenolic compounds}

The total concentration of phenolic compounds extracted with solvents including water, $80 \%$ methanol, 50\% ethanol and acetone were compared in a $12 \mathrm{~h}$ period using maceration method as shown in Table 2.

Table 2. Total phenolic compounds extracted from dried POME by maceration method

\begin{tabular}{ccccc}
\hline $\begin{array}{c}\text { Solvent } \\
\text { Time, }\end{array}$ & Water & Methanol 80\% & Ethanol 50\% & Acetone \\
\hline 2 & $121.8 \pm 0.2$ & $138.4 \pm 0.4$ & $163.2 \pm 0.4$ & $53.5 \pm 0.6$ \\
4 & $123.5 \pm 0.4$ & $139.2 \pm 0.6$ & $163.8 \pm 0.4$ & $54.2 \pm 0.4$ \\
6 & $125.3 \pm 0.3$ & $139.8 \pm 0.3$ & $164.1 \pm 0.6$ & $54.5 \pm 0.3$ \\
8 & $125.7 \pm 0.3$ & $139.3 \pm 0.5$ & $164.4 \pm 0.6$ & $53.9 \pm 0.7$ \\
10 & $126.1 \pm 0.4$ & $140.1 \pm 0.7$ & $164.1 \pm 0.4$ & $54.2 \pm 0.4$ \\
12 & $125.9 \pm 0.4$ & $140.3 \pm 0.6$ & $164.7 \pm 0.5$ & $54.3 \pm 0.3$ \\
\hline
\end{tabular}

${ }^{*}$ Total phenolic content expressed as $\mathrm{mg}$ (GAE) per $10 \mathrm{~g}$ of lyophilized POME 
Ethanol (50\%) gave the best extraction yield compared to the other solvents. Since there were no significant differences in the phenolic concentration when comparing the different extraction times $(2,4,6,8,10$ and $12 \mathrm{~h})$, it can be deduced that the optimal time for extraction of phenolic compounds is $2 \mathrm{~h}$ with yield of $163.2 \mathrm{mg}$ GAE per $10 \mathrm{~g}$ of lyophilized POME. Owing to the fact that polyphenols are mostly polar compounds, highly-polar solvents (e.g. water) and non-polar ones (e.g. chloroform and hexane) are not appropriate for extracting a high phenolic content. Moreover, the use of water as the only solvent yields an extract with a high content of impurities (e.g. organic acids, sugars, soluble proteins) along with phenolic compounds which could interfere in the phenolic identification and quantification. On the other hand, the absolute alcoholic solvents decrease extraction yield. So, application of water combined with other organic solvents makes it a moderately polar medium ensuring the optimal conditions for extraction of polyphenols ${ }^{32}$. Acetone could not be a suitable solvent in extracting polar compounds like phenols due to its non polar entity and based on what mentioned above, it is understood that methanol and ethanol extracts contain higher phenolics than water. Many studies carried out with other plant species have reported higher yield of phenolic concentration using polar solvents compared with the nonpolar ones ${ }^{33,34}$. As seen in Tables 2, there was no particular correlation between increasing of time and yield extraction. It is well known that, the final equilibrium will be achieved between the solute concentrations in the matrix and in the bulk solution (solvent) after a certain time. Thus, an excessive extraction time is not useful to extract more phenolic compounds and prolonged extraction process might lead to phenolics oxidation due to light or oxygen exposure ${ }^{35}$. In the Microwave Irradiation Extraction (MIE) method, as done in maceration, the type of solvent, the extraction time and yield was studied as shown in Table 3.

Table 3. Total phenolic compounds extracted from dried POME by non-enzymatic microwave irradiation extraction (MIE) method

\begin{tabular}{ccccc}
\hline $\begin{array}{c}\text { Solvent } \\
\text { Cycles of exposure }\end{array}$ & Water & Methanol 80\% & Ethanol 50\% & Acetone \\
\hline 3 & $129.8 \pm 0.2$ & $140.4 \pm 0.8$ & $176.8 \pm 0.4$ & $55.5 \pm 0.5$ \\
6 & $132.6 \pm 0.4$ & $144.2 \pm 0.7$ & $180.6 \pm 0.3$ & $57.2 \pm 0.4$ \\
9 & $135.3 \pm 0.7$ & $148.8 \pm 0.3$ & $188.6 \pm 0.6$ & $58.5 \pm 0.3$ \\
12 & $136.1 \pm 0.3$ & $152.1 \pm 0.5$ & $190.7 \pm 0.5$ & $59.0 \pm 0.8$ \\
15 & $136.3 \pm 0.3$ & $153.7 \pm 0.4$ & $190.9 \pm 0.4$ & $59.2 \pm 0.3$ \\
\hline
\end{tabular}

${ }^{*}$ Total phenolic content expressed as $\mathrm{mg}$ (GAE) per $10 \mathrm{~g}$ of lyophilized POME

The extraction using exposure of microwave at $180 \mathrm{~W}$ for 12 cycles and 15 cycles $(20 \mathrm{~s}$ per cycle) were found to be with no significant difference. The $50 \%$ ethanol presented the highest yield at 12 cycles of microwave irradiation (190.7 mg TAE/10g dry POME) and for the $80 \%$ methanol extraction at 12 cycles exposure the phenolic yield was $152.1 \mathrm{mg}$ TAE/10 g dry POME. Water and acetone as extracting solvents gave the lowest yield of about 136.1 and $59.0 \mathrm{mg}$ TAE/10 g dry POME respectively. The results show that the yield for 12 cycles microwave irradiation extraction using $50 \%$ ethanol increase by $15.8 \%$ as compared to the maceration method.

In selecting the appropriate solvent type in MIE, several parameters like the target analyte solubility, the solvent-analyte interaction and dielectric properties of the solvent should be considered. Non-polar solvents are unaffected by microwave due to their lower dielectric constant and dissipation factor in comparison to the polar solvents, thus having no influence under microwave and provides no higher efficiency in extraction with $\mathrm{MIE}^{25}$. 
That is the reason why in case of using acetone as the extracting solvent, the amount of phenolic compounds was low. Besides, in a similar study it was found that less polar extracting solvents like hexane did not yield a high efficient extraction of ginger with MIE ${ }^{25}$. Water undergoes greater microwave absorption due to its high dielectric constant. Both ethanol and methanol have lower values than water, yet show higher heating efficiency when applied in a water mixture combination. In another study, phenolic compounds and antioxidants were obtained from buckwheat by microwave using different solvents, such as water, ethanol and a water-ethanol mixture; the water-ethanol mixture was found to give the best results ${ }^{24}$. As stated earlier, the use of water as the only solvent yields an extract with a high content of impurities (e.g. organic acids, sugars, soluble proteins) along with phenolic compounds which could interfere in the phenolic identification and quantification. On the other hand, the absolute alcoholic solvents decrease extraction yield. So, application of water combined with other organic solvents makes it a moderately polar medium ensuring the optimal conditions for extraction of polyphenols ${ }^{32}$. In comparison of these two methods, MIE had higher extraction efficiency with reduced extraction time. It was shown that a 5-6 min extraction time was enough for complete leaching of the phenolic compounds using microwave irradiation. This shows that all the extractable phenolics readily diffused to the solvent in microwave extraction.

In the microwave irradiation extraction (MIE) aided with ragi tapai hydrolysis method, as done previously, experiments were performed to study the effects of type of solvent, the extraction time and yield as shown in Table 4.

Table 4. Total phenolic compounds extracted from dried POME by enzymatic hydrolysis and microwave irradiation extraction (MIE) method

\begin{tabular}{ccccc}
\hline $\begin{array}{c}\text { Solvent } \\
\text { Cycles of exposure }\end{array}$ & Water & Methanol 80\% & Ethanol 50\% & Acetone \\
\hline 3 & $136.6 \pm 0.2$ & $148.3 \pm 0.8$ & $198.3 \pm 0.2$ & $59.5 \pm 0.5$ \\
6 & $141.6 \pm 0.5$ & $154.4 \pm 0.2$ & $207.6 \pm 0.5$ & $63.6 \pm 0.4$ \\
9 & $146.3 \pm 0.5$ & $157.2 \pm 0.3$ & $217.4 \pm 0.6$ & $68.7 \pm 0.5$ \\
12 & $148.4 \pm 0.3$ & $159.1 \pm 0.4$ & $221.7 \pm 0.5$ & $69.0 \pm 0.9$ \\
15 & $147.9 \pm 0.2$ & $159.7 \pm 0.7$ & $221.9 \pm 0.4$ & $69.2 \pm 0.4$ \\
\hline
\end{tabular}

${ }^{*}$ Total phenolic content expressed as $\mathrm{mg}$ (GAE) per $10 \mathrm{~g}$ of lyophilized POME

As before, the extraction using exposure of microwave at $180 \mathrm{~W}$ for 12 cycles and 15 cycles (20 s per cycle) were found to be with no significant difference. The $50 \%$ ethanol presented the highest yield at 12 cycles of microwave irradiation (221.7 mg TAE/10 g dry POME). This shows that the yield of phenolic compounds increase by $16.3 \%$ as compared to microwave irradiation without enzymatic hydrolysis and increase by $34.7 \%$ when compared with maceration method.

It is anticipated that at low power level of microwave irradiation non-thermal effects of microwave play a role. At low power level the active site of the enzyme molecules may undergo conformational changes to favor the cleavage of the glycosidic bonds. This will enhance the efficiency of the enzyme. Non-thermal effects or microwave effect has been observed in a number of microwave assisted catalytic or enzymatic reactions ${ }^{36-38}$. The low level of microwave power used in this extraction, was to avoid the enzyme denaturation and to minimize the thermal effects of the microwave irradiation. Besides that, the microwave irradiation alone also helps to loosen the compact matrix structure of solids in which some phenolic compounds are trapped. With the microwave and enzymatic action all the trapped 
phenolic compound would be free and then easily available for extraction. This bring about the higher amount of phenolic compound extracted with microwave aided enzymatic extraction method.

\section{Conclusion}

Ragi tapai was chosen based on its high content of moulds which are rich in hydrolytic enzymes. Hence ragi tapai provide a cheaply and readily available stock the hydrolytic enzymes to make the extraction process more efficient.

The present study had highlighted the importance of well controlled microwave assisted enzymatic extraction to enhance the overall yield. It is worth to point out some general statements: (1) Enzymatic hydrolysis of starch using typical enzymes may successfully be carried out at microwave condition. (2) The effect of microwave irradiation strongly depends on the microwave power level - higher levels of MW may cause denaturation of the enzyme. (3) The dominant factor inthe microwave assisted reaction in this study may be treated as non-thermal effects. (4) The Microwave Irradiation-Enzyme Coupling Catalysis (MIECC) effecton ethanol production had shown an reaction rate increase of close to two times. Therefore, phenolic compounds were extracted in a very short time. Microwaves increase the internal pressure of solid media and enhance the extraction; thus, phenolic compounds can be leached in shorter times by microwave when compared to conventional extraction $^{39}$. Hence microwave irradiation was able to reduce extraction time by 20 fold as compared to maceration method. Shorter extraction time in microwave processing might have reduced the deterioration of phenolic compounds when compared to conventional extraction. Long extraction times and high temperature increase the chance of oxidation of phenolics which decrease the yield of phenolics in the extracts ${ }^{40}$.

\section{References}

1. Vijayaraghavan K, Ahmad D and Abdul Aziz M E, J Environ Manage., 2007, 82(1), 24-31; DOI:10.1016/j.jenvman.2005.11.016

2. Ma A N, Cheah S C and Chow M C, Waste Management in Malaysia: Current Status and Prospects for Bioremediation, 1993, 111-136.

3. MPOB, (2008b), Number of mills and capacity: 2008; http://econ.mpob.gov.my/economy/annual/stat2008/ei_processing08.htm

4. $\quad \mathrm{Ng}$ M H and Choo Y M, Am J Appl Sci., 2012, 9(11), 1862-1867.

5. Goh S H, Choo Y M and Ong A S H, J Am Oil Chem Soc., 1985, 62(2), 237-240; DOI:10.1007/BF02541384

6. Ng M H, Choo Y M, Ma A N, Chuah C H and Hashim M A, Malaysian J Sci., 2006, 25, 139-145.

7. $\mathrm{Ng}$ M H, Choo Y M, Ma A N, Chuah C H and Hashim M A, J Am Oil Chem Soc., 2009, 86(3), 201-205; DOI:10.1007/s11746-009-1345-Z

8. Choo Y M, Ng M H, Ma A N, Chuah C H and Hashim M A, Lipids, 2005, 40(4), 429-432; DOI:10.1007/s11745-006-1400-6

9. Neo Y P, Ariffin A, Tan C P and Tan Y A, Int J Food Sci Technol., 2008, 43(10), 1832-1837; DOI:10.1111/j.1365-2621.2008.01717.x

10. Sundram K, Sambanthamurthi R and Tan Y A, Asia Pacific J Clin Nutr., 2003, 12(3), 355-362.

11. Sambanthamurthi R, Tan Y A and Sundram K, Treatment of vegetation liquors derived from oil-bearing fruit, United States Patent US, 2008, 7,387,802 B2, Malaysian Palm Oil Board. 
12. Ma A N, Ong A S H, Biol Wastes, 1988, 23(2), 85-97;

DOI:10.1016/0269-7483(88)90066-3

13. Ma A N, Environmental Management for the Oil Palm Industry, Palm Oil Dev., 2000, 30, 1-10.

14. Ahmad A, Ismail V and Bhatia S, Desalination, 2003, 157(1-3), 87-95; DOI:10.1016/S0011-9164(03)00387-4

15. Pinelo M, Zornoza B and Meyer A S, Sep Purifn Technol., 2008, 63(3), 620-627; DOI:10.1016/j.seppur.2008.07.007

16. Puri M, Sharma D and Barrow C J, Trends Biotechnology, 2011, 30(1), 37-44; DOI:10.1016/j.tibtech.2011.06.014

17. Pinelo M, Arnous A and Meyer A S, Trends Food Sci Tech., 2006, 17(11), 579-590. DOI:10.1016/j.tifs.2006.05.003.

18. Li B B, Smith B and Hossain M, Sep Purif Technol., 2006, 48(2), 189-196; DOI:10.1016/j.seppur.2005.07.019

19. Stalikas C D, J Sep Sci., 2007, 30(18), 3268-3295; DOI:10.1002/jssc.200700261

20. Le Bourvellec C, Guyot S and Renard C M G C, Carbohyd Polym., 2009, 75(2), 251-261; DOI:10.1016/j.carbpol.2008.07.010

21. Wang L and Weller C L, Trends Food Sci Technol., 2006, 17(6), 300-312; DOI:10.1016/j.tifs.2005.12.004

22. Proestos C and Komaitis M, Food Sci Techol-LEB., 2008, 41(4), 652-659; DOI:10.1016/j.lwt.2007.04.013

23. Orsat V and Raghavan V, Microwave technology for food processing: an overview. In: The Microwave Processing of Foods (Eds. Schubert H and Regier M), Woodhead Publishing, Cambridge, England, 2005, 105-115.

24. Inglett G E, Rose D J, Chen D, Stevenson D G and Biswas A, Food Chem., 2010, 119(3), 1216-1219; DOI:10.1016/j.foodchem.2009.07.041

25. Mandal V, Mohan Y and Hemalatha S, Pharmacogn Rev., 2007, 1(1), 7-18.

26. Jain R, Nandakumar K, Srivastava V, Vaidya S K, Patet S and Kumar P, Pharmacology Online, 2008, 2, 411-427.

27. Gandjar I, Tapai from cassava and cereals, Proceedings of the 1st International Symposium and Workshop on Insight into the World of Indigenous Fermented Foods for Technology Development and Food Safety, Aug. 13-17, Kasetsart University, 2003, 1-10; http://www.agriqua.doae.go.th/worldfermentedfood/I_10_Gandjar.pdf

28. APHA, AWWA and WPCF, Standard Method for Examination of Water and Wastewater, $17^{\text {th }}$ Ed., American Public Health Association, Washington, D.C., 1992.

29. Gharekhani M, Rafiee Z, Ghorbani M and Jafari S M, Open vessel microwave system for extraction of analytes from medicine plants, Iran patent No 59321 (in Iran), 2009.

30. Singleton V L, Orthofer R and Lamuela-Raventos R.M, Methods Enzymol., 1999, 299, 152-178; DOI:10.1016/S0076-6879(99)99017-1

31. Laohaprapanon T, Prasertsan P and Kittikun A H, Asian J Energy Environ., 2005, 6(1), 39-55.

32. Chirinos R, Rogez H, Campos D, Pedreschi R and Larondelle Y, Sep Purif Technol., 2007, 55(2), 217-225; DOI:10.1016/j.seppur.2006.12.005

33. Trabelsi N, Megdiche W, Ksouri R, Falleh H, Oueslati S, Soumaya B, Hajlaoui H and Abdelly C, LWT- Food Sci Technol., 2010, 43(4), 632-639; DOI:10.1016/j.lwt.2009.11.003

34. Franco D, Sineiro J, Rubilar M, Sánchez M, Jerez M, Pinelo M, Costoya N and Núñez M J, Agric Food Chem., 2008, 7(8), 3210-3216. 
35. Chan S W, Lee C Y, Yap C F, Wan Aida W M and Ho C W, Int Food Res J., 2009, 16(2), 203-213.

36. La Hoz D, Diaz-Ortiz A and Moreno A, J Microw Power Electromag Energy, 2007, 41, 44-64. PMID: 18161416

37. Yadav G D and Lathi, P, Clean Technol Environ Policy, 2007, 9(4), 281-287; DOI:10.1007/s10098-006-0082-3

38. Saifuddin N, Zhan L W and Ning K X, Am J Appl Sci., 2011, 8(3), 217-229; DOI:10.3844/ajassp.2011.217.229

39. Bayramoglu B.; Sahin, S.; Sumnu G, J Food Eng., 2008, 88(4), 535-540; DOI:10.1016/j.jfoodeng.2008.03.015

40. Dai J and Mumper R, Molecules, 2010, 15(10), 7313-7352. 